\title{
Interaction between the DNA model base 9-ethylguanine and a group of ruthenium polypyridyl complexes: kinetics and conformational temperature dependence
}

Eva Corral ${ }^{a}$, Anna C. G. Hotze ${ }^{a \#}$, Alessandra Magistrato ${ }^{b}$ and Jan Reedijk ${ }^{a^{*}}$.

(a) Leiden Institute of Chemistry, Gorlaeus Laboratories, Leiden University, P.O. Box 9502, 2300 RA Leiden, The Netherlands and (b) CNR-INFM-Democritos and International School for Advanced Studies, Trieste, Italy.

*To whom correspondence should be addressed. E-mail: Reedijk@chem.leidenuniv.nl. Fax: +31 71 5274671.

\#Current address: School of Chemistry, University of Birmingham, Edgbaston, Birmingham B15 2TT.

\section{Supporting information}




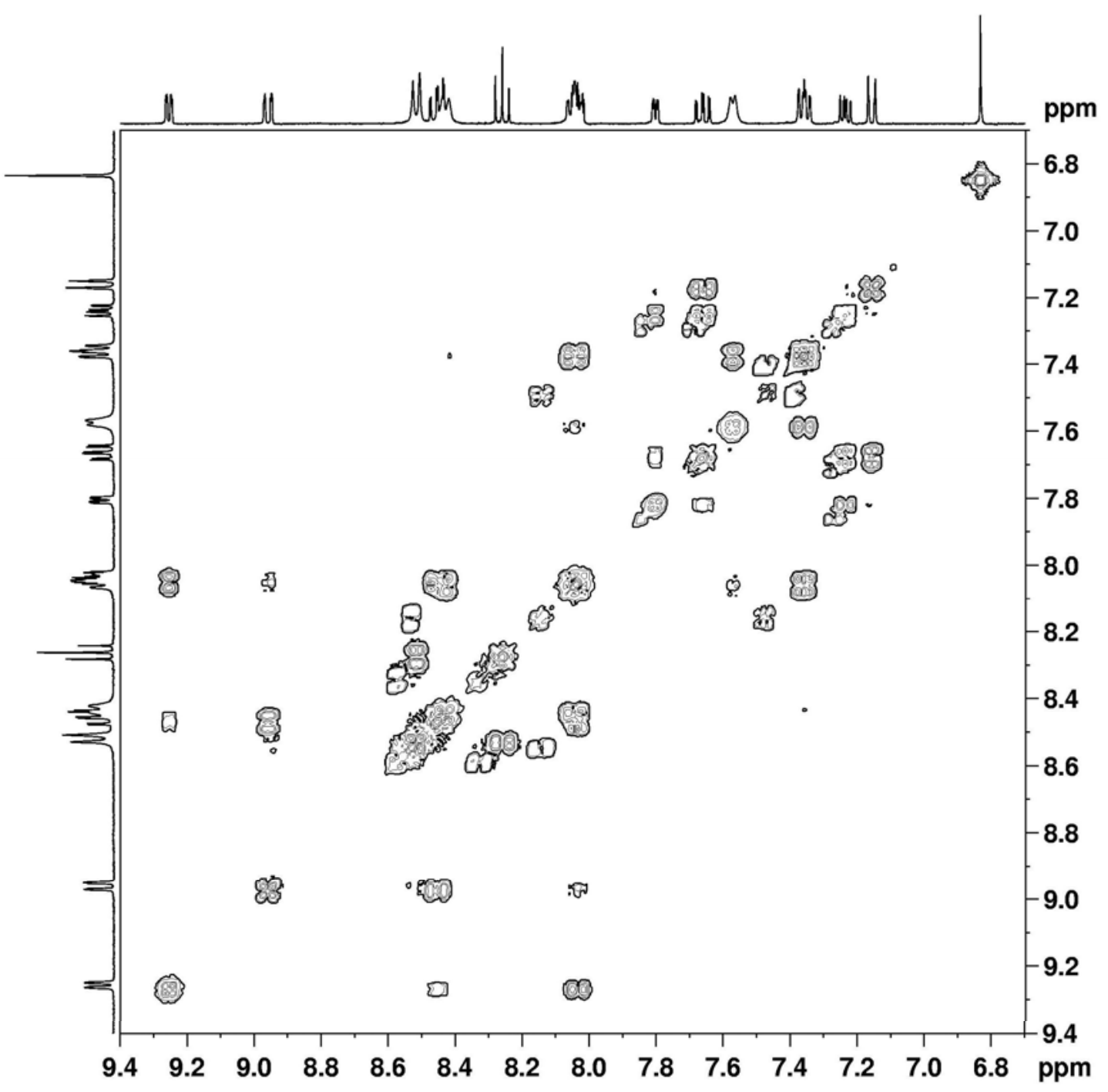

Supporting information Figure 1. Aromatic region of the ${ }^{1} \mathrm{H}-{ }^{1} \mathrm{H}$ COSY spectrum of $\mathbf{1 d}$ in $\mathrm{MeOH}-\mathrm{d}_{4}$ at $328 \mathrm{~K}$ 


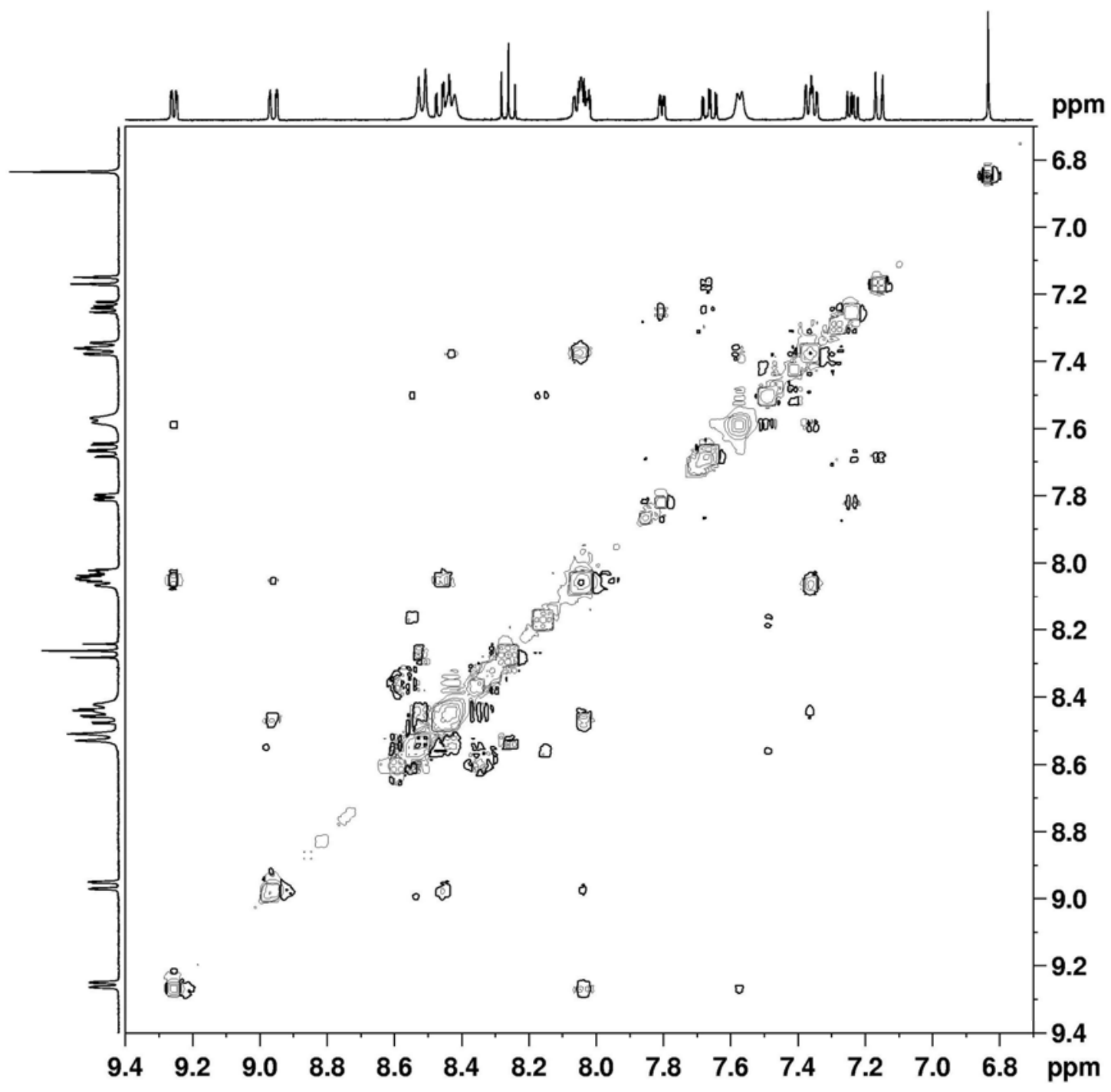

Supporting information Figure 2. Aromatic region of the ${ }^{1} \mathrm{H}-{ }^{1} \mathrm{H}$ NOESY spectrum of $1 \mathbf{d}$ in $\mathrm{MeOH}-\mathrm{d}_{4}$ at $328 \mathrm{~K}$ 